\title{
The Co-Regulation of Emotions Between Mothers and their Children with Autism
}

\author{
Amanda C. Gulsrud · Laudan B. Jahromi • \\ Connie Kasari
}

Published online: 28 August 2009

(C) The Author(s) 2009. This article is published with open access at Springerlink.com

\begin{abstract}
Thirty-four toddlers with autism and their mothers participated in an early intervention targeting joint engagement. Across the 24 intervention sessions, any significant distress episode in the child was coded for emotion regulation outcomes including child negativity, child emotion self-regulation, and mother emotion co-regulation. Results revealed that emotion regulation strategies by both mother and child were employed during distress episodes. An effect of intervention was found such that children decreased their expression of negativity across the intervention and mothers increased their emotional and motivational scaffolding. The results of this study indicate a positive effect of an intervention targeting joint engagement on emotion co-regulation outcomes.
\end{abstract}

The study was supported by a grant from the Department of Health and Human Services, National Institute of Health MH-01-010 awarded to Connie Kasari, Ph.D. Thanks to undergraduate students Joanna L. Quach, Araceli Berenice Urena, and Janett Castillo. Special thanks to the families and children who participated in the study. Results of this study were presented at the Society for Research on Child Development (SRCD) conference in Denver, Colorado in 2009. This work is adapted from a dissertation by the same title.

\section{A. C. Gulsrud · C. Kasari}

Semel Institute for Neuroscience and Human Behavior,

University of California, Los Angeles, CA, USA

L. B. Jahromi

The School of Social and Family Dynamics,

The Arizona State University, Tempe, AZ, USA

C. Kasari $(\square)$

Graduate School of Education and Information Studies, University of California, 3132 Moore Hall, Los Angeles, CA 90024, USA

e-mail: kasari@gseis.ucla.edu
Keywords Autism - Emotion regulation . Early intervention

\section{Introduction}

Mothers facilitate the emotional development of their children by supporting, scaffolding, and modeling their children's emerging emotional understanding, emotional expression, and modification of these emotions. Mothers may play a particularly crucial role in this process when their child has a disorder, such as autism, that is characterized by delayed or deviant patterns of emotional development. This study explores the development of emotion co-regulation in young children with autism and their mothers within the context of an early social-communication intervention. The construct of emotion regulation used in the present study refers to "the extrinsic and intrinsic processes responsible for monitoring, evaluating, and modifying emotional reactions" (Thompson 1994). Important to this definition is the emphasis on both extrinsic and intrinsic processes, which may include both internal or selfdriven processes, and external or mother-driven support.

Several studies have begun to examine the development of emotion regulation in children with autism. Parent report measures indicate children with autism score with more deviant ratings in the domains of self-regulation and affective sharing compared to children with Down syndrome and these scores remain stable over a two-year period (Bieberich and Morgan 2004). Parents also rate children with ASD as more temperamentally difficult, slower to adapt, less persistent, less able to focus and shift attention, and more easily distracted when compared to typically matched peers (Bailey et al. 2000; Capps et al. 1993; Konstantareas and Stewart 2006). Behavioral coding of children with autism during a 
mildly frustrating task show these children employing fewer adaptive strategies and a greater range of strategies compared with typical controls (Konstantareas and Stewart 2006).

It has also been suggested that child and maternal characteristics may relate to the development of emotion regulation in children with autism. Research on problem behaviors of young children with autism suggests that maladaptive behaviors significantly predict maternal stress (Tomanik et al. 2004). Little is known about the role maternal stress plays in the development of emotion selfregulation in the child. What is known is that high levels of stress interfere with sensitive and responsive parenting, and therefore, it is plausible that stress may also interfere with the maternal support of emotion regulation in the child (Belsky 1984).

Several core features of autism may be related to the challenges noted in the domain of emotion regulation. For one, deficits in joint attention may be linked with selfregulation difficulties in children with autism. An underlying component of joint attention is the regulation of attentional and affective processes in order to coordinate gestures, eye-contact, and emotional expressions. In typical development, infants and young children learn to regulate arousal and attention by coordinating communicative gestures between self and others. For example, Morales et al. (2005) found that joint attention skills, particularly the ability to follow the direction of a mother's gaze at 6 months, were related to children's use of effective emotion regulation strategies at 2 years of age, and that coordination of joint attention and emotion regulation were related concurrently at 2 years of age. Similarly, Raver (1996) found that typical children who were able to engage in more joint attention during free-play with their mothers were more likely to engage in distraction self-regulation techniques during a delay of gratification task. The link between joint attention and emotion self-regulation in the typical literature suggests that children who rarely engage in joint attention, such as children with autism, may be at risk for having difficulty in the area of emotion selfregulation.

Affective disturbances in children with autism also may play a critical role. Compared to typical children, children with autism engage in more frequent displays of negative affect and less clear emotional signals during social interactions (e.g., Yirmiya et al. 1989). This profile may have deleterious effects on the mother-child relationship by decreasing the ability for the mother to "read" and react to the emotional signals of the child. If mothers struggle to understand and interpret emotional signals in the child this may lead to less parental support of new skills and capacities, including new regulatory skills (Stansbury and Zimmermann 1999).
Several studies find that mothers adapt to the particular presenting characteristics of their children. For example, they respond to the communication and attentional bids of their child with autism in similar style and frequency to mothers of children with typical development or other disabilities when children are matched on developmental age (Kasari et al. 1988; Adamson et al. 2001). In addition, mothers of children with autism and those of typical children are both able to synchronize their behaviors to their children's attention and activities, and follow the child's interest to a similar degree (Watson 1998; Siller and Sigman 2002). Mothers of children with autism also appear to differentially respond to the developmental differences in their children by adapting both behavioral and verbal scaffolding to the child's individual needs (Kasari et al. 1988; Konstantareas et al. 1988). Thus it appears that mothers of young children with autism are quite skilled in their interactions with their children and are important agents of change who should be a focus of intervention efforts. Indeed, interventions targeting joint attention using mothers as the agents of change have demonstrated positive effects on children's social communication behaviors (Aldred et al. 2004; Drew et al. 2002). Given the associations between joint attention and emotion regulation, an important question is whether a caregiver-based joint attention intervention could have positive effects on caregivers' emotion co-regulation behaviors and their children's self-regulation skills.

The current study examines emotion self-regulation in toddlers and maternal scaffolding strategies in 34 motherchild dyads during an early intervention targeting joint engagement and joint attention in young children with autism. Throughout the course of intervention, mothers were taught to initiate and maintain a joint topic of attention with their child. This intervention was based upon a previously successful joint attention intervention aimed at changing joint attention skills in the children themselves via an experimenter-child treatment approach (Kasari et al. 2006). The interventionists used a developmental approach and taught mother-child dyads at the developmental level that was appropriate for the child.

Although emotion regulation was not a specific topic targeted in intervention, the construct was embedded within many of the explicit teaching techniques in the intervention and emerged as an important theme in many of the sessions. As the ultimate goal of the intervention was to increase the episodes of joint engagement between mother and child surrounding common areas of focus, it became important to explore how both the mother and child negotiated difficult points in the interaction when the child's emotions were dysregulated.

The construct of emotion regulation encompasses both affective expression (duration, intensity, frequency) and specific behavioral strategies (e.g., gaze aversion) measured 
in a temporal evaluation of emotional change. The current study coded specific toddler and mother behaviors and strategies during episodes of negativity in the child. Therefore, sessions identified with significant distress episodes throughout the course of intervention were coded behaviorally for child negativity, child emotion self-regulation, and maternal emotional co-regulation. In addition, mothers were rated globally for motivational and emotional scaffolding abilities. Relationships between emotion regulation outcomes and child (behavior problems) and maternal characteristics (stress) also were explored. The mother was expected to play a critical role during these negative episodes as the children in the current study were chronologically young and developmentally delayed. In addition, the mother-child context allowed for a naturalistic exploration of both mother and child reactions and negotiations of difficult and perhaps frustrating episodes during play. The researchers predicted that mothers would display specific emotion co-regulation strategies during child distress and that the intervention would help ameliorate child dysregulation.

\section{Methods}

\section{Participants}

The participants included 34 mother-child pairs from an existing intervention study for toddlers diagnosed with ASD and their mothers (Eunice Kennedy Shriver National Institute of Child Health and Human Development; National Institute of Mental Health 2009). Forty-two children were screened for participation and of these, 38 children qualified for the study and were consented to participate. Each of these children met study criteria for autism spectrum disorder on the Autism Diagnosis Interview-Revised (ADI-R; Lord et al. 1994) and the Autism Diagnosis Observation Schedule (ADOS; Lord et al. 1989) and was under the age of 36 months. Children were excluded from the study if they had seizures, sensory or physical disorders, and/or comorbidity with any other psychological disorder or disease. Participants were randomly assigned to one of two conditions; either immediate treatment using a mother-based joint attention intervention, IT $(n=19)$ or a waitlist control condition, WL $(n=19)$. Of these 38 children, 35 children ( $n=19$ from IT and $n=16$ from WL) completed all assessments and the mother-based joint attention intervention sessions. Three children dropped from the waitlist control condition prior to intervention due to busy schedules. One additional child was excluded due to inadequate videotape footage of his intervention sessions.

Table 1 summarizes the relevant demographics for both the toddlers and their mothers who participated in the
Table 1 Participant demographics prior to intervention

\begin{tabular}{ll}
\hline & Intervention participants $(N=34)$ \\
\hline Chronological age & $30.6(4.0)$ \\
Mental age $^{\text {a }}$ & $19.2(6.5)$ \\
Developmental quotient & $62.5(19.2)$ \\
Gender (Males/Females) & $26 / 8$ \\
Ethnicity (White/Minority) & $19 / 15$ \\
Mother's age & $34.5(4.5)$ \\
Mother's highest level of education \\
Special training & 1 \\
Some college & 3 \\
College & 21 \\
College/professional training & 9 \\
Days in intervention & $69.4(26.0)$ \\
Child Behavior Checklist (CBCL) \\
Total & $58.9(10.0)$ \\
Internalizing domain & $60.2(11.1)$ \\
Externalizing domain & $52.9(9.8)$ \\
Parental Stress Index (PSI) & \\
Total & $248(48.8)$ \\
Child domain & $131.3(25.5)$ \\
Parent domain & $116.8(27.7)$ \\
\hline Note: Using Mulen (1995) Scales &
\end{tabular}

Note: ${ }^{a}$ Using Mullen (1995) Scales of Early Learning

intervention. The children were recruited from a middle class area in the Western United States. They ranged in chronological age from 21 to 36 months old with an average age of 30.6 months. The average mental age was 19 months, approximately $40 \%$ of children were from ethnic minority backgrounds and 26 children were males. No exclusions were made based upon gender or ethnicity. The majority of mothers had completed college, had graduate or professional training, and their average age was 34.5 years. There were no statistically significant differences between immediate and waitlist control treatment groups in pretreatment characteristics including chronological age, mental age, developmental IQ, or mother's age, and education.

\section{Procedure}

All participants received the same mother-mediated joint attention intervention. Dyads that initially were randomized to the waitlist condition were asked to participate in an 8-week waiting period before beginning the intervention. The intervention was designed to be carried out 3 days a week for 8 weeks in a well-stocked laboratory playroom. Mothers were recruited from local community agencies and regional centers. The intervention consisted of 10 modules, each targeting specific early joint attention, language skills, and joint engagement with the mother. Specific content of the intervention can be found in Eunice Kennedy Shriver 
National Institute of Child Health and Human Development; National Institute of Mental Health 2009.

During the 24 intervention sessions, the modules were introduced to the mother by a trained interventionist. The last 10 min of every session consisted of a mother-child play period during which the interventionist would withhold any feedback and would tape the session. This $10 \mathrm{~min}$ interaction allowed for consistent and standardized observation and coding of child and mother behaviors.

Emotion regulation outcomes were behaviorally and globally coded during these videotaped sessions. First, each videotaped interaction was screened for the presence or absence of any distress episodes. A distress episode is identified as any interaction between mother and child where the child expresses facial/bodily and/or vocal negativity. Sessions identified with at least one distress episode lasting at least $30 \mathrm{~s}$ were coded using a time sampling method in 10-s epochs for child negativity, child emotion self-regulation strategies, and maternal co-regulation strategies. The entirety of each session identified with at least one distress episode was behaviorally coded. Sessions were coded in a random order by coders blind to treatment goals and study hypotheses. Two independent trained coders observed $20 \%$ of the videotapes to assess inter-rater reliability. An alpha $(\alpha)$ value was computed for each child and maternal behavior (See Tables 2 and 3 for inter-rater reliabilities). Thus, each mother-child dyad has a possible total of 24 sessions behaviorally coded for emotion regulation

Table 2 Descriptions of child emotion self-regulation strategies

\begin{tabular}{|c|c|c|}
\hline Behavior & Alpha & Definition \\
\hline $\begin{array}{l}\text { Cognitive/verbal } \\
\text { self-soothing }\end{array}$ & 1 & $\begin{array}{l}\text { Statements or activities indicating the use of cognitive reappraisals or verbal self-soothing (e.g., I'm a big } \\
\text { girl", "I can do it"). }\end{array}$ \\
\hline Physical self-soothing & .63 & $\begin{array}{l}\text { Bodily-directed behaviors and use of soft or familiar objects (e.g., thumb-sucking, hair-twisting, stroking own } \\
\text { shirt). }\end{array}$ \\
\hline Idiosyncratic behaviors & .78 & $\begin{array}{l}\text { Repetitive unusual behaviors with no apparent instrumental focus (e.g., handflapping, rocking body, tonguing } \\
\text { behaviors, biting) }\end{array}$ \\
\hline $\begin{array}{l}\text { Physical venting/tension } \\
\text { release }\end{array}$ & .63 & High-energy behavior with no apparent instrumental focus (e.g., humming, kicking legs fast). \\
\hline Avoidance & .92 & $\begin{array}{l}\text { Behaviors indicative of avoiding the task at hand (e.g., twisting or turning body away from puzzle, attempting } \\
\text { to get out of seat). }\end{array}$ \\
\hline Distraction & .84 & $\begin{array}{l}\text { When the child's focus of attention is a away from the puzzle, and on him/herself (e.g., own hand) or on } \\
\text { another object/place in the room. }\end{array}$ \\
\hline Maternal orientation & .97 & $\begin{array}{l}\text { When the child's focus of attention is on the experimenter. The child looks to the experimenter with no } \\
\text { vocalization. If the child also vocalizes, his/her vocalization is additionally coded as one of the following } \\
\text { two codes. }\end{array}$ \\
\hline $\begin{array}{l}\text { Other-directed comfort } \\
\text { seeking }\end{array}$ & .77 & $\begin{array}{l}\text { Vocalization indicating comfort-seeking or behavioral evidence of such (e.g., wanting to be held, reclining in } \\
\text { experimenter's lap. }\end{array}$ \\
\hline $\begin{array}{l}\text { Other-directed assistance } \\
\text { seeking }\end{array}$ & .91 & $\begin{array}{l}\text { Vocalization or behavioral evidence of requesting assistance (e.g., "What's this?", "Where does this go", } \\
\text { "Help me"). }\end{array}$ \\
\hline
\end{tabular}

Table 3 Descriptions of maternal emotion co-regulation strategies

\begin{tabular}{|c|c|c|}
\hline Behavior & Alpha & Definition \\
\hline Prompting/helping & .98 & $\begin{array}{l}\text { Mother physically or vocally prompts and scaffolds child (e.g., physical prompting with toy if child becomes } \\
\text { frustrated) }\end{array}$ \\
\hline $\begin{array}{l}\text { Following the } \\
\text { child's lead }\end{array}$ & .97 & $\begin{array}{l}\text { Mother is sensitive to child's interests and follows the child to his/her desired toy/activity (e.g., Mom may appear } \\
\text { to wait for child to choose a toy and then insert herself into interaction) }\end{array}$ \\
\hline $\begin{array}{l}\text { Redirection of } \\
\text { attention }\end{array}$ & .95 & $\begin{array}{l}\text { Mother distracts the child or directs the child's attention away from negative stimulus (e.g., pointing out other toys } \\
\text { in room) }\end{array}$ \\
\hline Active ignoring & .92 & $\begin{array}{l}\text { Mother actively ignores child during distress episodes (e.g., mom may continue to play with a toy or purposely } \\
\text { turn away from child) }\end{array}$ \\
\hline Reassurance & .83 & $\begin{array}{l}\text { Mother reassures or encourages child surrounding frustrating or negative activity (e.g., "It's okay. You can do } \\
\text { it!") }\end{array}$ \\
\hline Emotional following & .94 & $\begin{array}{l}\text { Mother's reflection, extension or elaboration upon child's distress or preoccupation (e.g., "I know you want the } \\
\text { toy") }\end{array}$ \\
\hline Physical comfort & .98 & Mother initiates behaviors to comfort child (e.g., hugging, kissing, picking up the child, rocking) \\
\hline Vocal comfort & .98 & Mother initiates vocalizations to comfort the child (e.g., sshhing, singing, sing-song voice) \\
\hline
\end{tabular}


outcomes, but the actual number of sessions coded varied from dyad to dyad depending on the identification of distress episodes. In addition, a global rating scale of maternal emotional and motivational scaffolding was used to assess maternal scaffolding during the sessions with identified distress episodes (Maslin-Cole and Spieker 1990).

\section{Behavioral Coding}

\section{Child Negativity}

Child negativity was coded in 10 -s epochs. Facial and bodily negativity were each coded on a four point scale with zero as no sign of negativity and three as highly negative. Reliability for child negativity was $\alpha=.72$ for facial negativity and .84 for bodily negativity.

\section{Child Self-Regulation Strategies}

The child's emotion self-regulation strategies were adapted from a study of typical toddlers during episodes of negativity (Goldsmith and Rothbart 1996). The presence or absence of each strategy was coded in 10-s epochs and include, symbolic self-soothing, physical self-soothing, repetitive or idiosyncratic behaviors, tension release, avoidance, distraction, maternal orientation, other-directed comfort seeking, and other-directed assistance seeking (Table 2).

\section{Maternal Co-Regulation Strategies}

A series of maternal strategies was adapted from a study of typical toddlers and their mothers (Grolnick et al. 1998). The 10-min session was coded in 10-s epochs for the presence or absence (0/1) of each mother strategy: prompting/helping, following the child's lead, redirection of attention, active ignoring, reassurance, emotional following, physical comfort, vocal comfort (Table 3).

\section{Behavioral Strategy Combinations}

Previous studies have conceptually classified maternal and child regulatory behaviors based upon their believed function. Grolnick et al. (1996), characterized behaviors as active and sustained, comforting, or goal-directed. Active strategies included those behaviors that shift attention away from the negative stimuli and range from looking away to sustained toy play, comfort strategies were a set of behaviors focused on soothing or reassurance, and goal-directed behaviors were those believed to require symbolic or representational thought and to be aimed at a particular goal. Based upon this work, five new behavioral categories were created and used in all further analyses: (a) maternal vocal strategies consisting of the combination of maternal vocal comfort and reassurance; (b) maternal active strategies consisting of the combination of prompting/helping, redirection of attention, and physical comfort; (c) child comfort strategies consisting of physical self-comfort and comfort seeking; (d) child physical strategies consisting of tension release, avoidance, and distraction; and (e) child verbal strategies consisting of cognitive/verbal self-soothing and assistance seeking. Maternal emotional following was not included in a composite variable and was independently included in further analyses. See Tables 4 and 5 for descriptive statistics on composite emotion regulation behaviors.

\section{Global Rating Scale}

A global rating scale of maternal emotional and motivational scaffolding was also utilized and adapted from the Maternal Scaffolding Coding System (Maslin-Cole and Spieker 1990). The emotional scaffolding scale rates mothers on a 5-point scale on several dimensions including, acceptance, praise, sensitivity, and affective sharing. The motivational scaffolding scale similarly rates mothers on a 5-point scale on initial recruitment, engagement with task, mother persistence, mother attempts to direct attention, and encouragement and praise. Previously this measure has been used successfully with developmentally delayed populations (Baker and Crnic 2005). Two independent trained coders observed $20 \%$ of the videotapes to assess inter-rater reliability and achieved a reliability of $\alpha=.78$ for the emotional scaffolding scale and $\alpha=.85$ for the motivational scaffolding scale.

\section{Correlates of Maternal and Child Behaviors}

The Parenting Stress Index (PSI) (Abidin 1982) was used to obtain a measure of parent-reported stress. The PSI consists of two subscales, including one associated with parental characteristics and the other with child characteristics. The PSI has been used in previous studies with children with autism (e.g., Kasari and Sigman 1997). Adequate test-retest reliability and internal consistency have been reported (Abidin 1983).

The Child Behavior Checklist (CBCL) (Achenbach et al. 1987 ) is a parent-report measure used to evaluate a range of child behavioral and emotional problems. The CBCL consists of seven scales: Emotional reactivity, Anxious/ Depressed, Somatic complaints, Withdrawn, Sleep problems, Attention problems, and Aggression problems. In addition, the symptoms can be scored in two broad categories of internalizing or externalizing syndromes. The CBCL has well established reliability and validity and has been used previously with child populations with autism (Skovgaard et al. 2004). 
Table 4 Descriptive statistics for negativity and child emotion regulation strategies

\begin{tabular}{|c|c|c|c|c|c|c|c|c|}
\hline & \multicolumn{4}{|c|}{$\begin{array}{l}\text { Proportion of time during } \\
\text { negative episodes }\end{array}$} & \multicolumn{3}{|c|}{$\begin{array}{l}\text { Proportion of time during } \\
\text { non-negative episodes }\end{array}$} & \multirow{2}{*}{$\begin{array}{l}\text { Dependent } \\
\text { samples } \\
T \text { - values }\end{array}$} \\
\hline & $\mathrm{M}$ & SD & Range & Freq of child & $\mathrm{M}$ & SD & Range & \\
\hline \multicolumn{9}{|l|}{ Negativity } \\
\hline Intensity of facial/bodily negativity & .1 & .08 & $.02-.40$ & 34 & N/A & N/A & N/A & N/A \\
\hline Intensity of vocal negativity & .08 & .07 & $.01-.39$ & 34 & N/A & N/A & N/A & N/A \\
\hline \multicolumn{9}{|c|}{ Child individual emotion regulation strategies } \\
\hline Cognitive/verbal self- soothing & .0009 & .0004 & $.00-.02$ & 2 & .0001 & .0004 & $.00-.0001$ & $\mathrm{n} / \mathrm{s}$ \\
\hline Physical self-soothing & .01 & .01 & $.00-.05$ & 18 & .003 & .009 & $.00-.04$ & $\begin{array}{l}T(1,33)=3.09 \\
p<.01\end{array}$ \\
\hline Repetitive "Idiosyncratic" behaviors & .03 & .04 & $.00-.13$ & 19 & .02 & .03 & $.00-.10$ & $\begin{array}{l}T(1,33)=2.07 \\
p<.05\end{array}$ \\
\hline Physical venting/tension release & .16 & .17 & $.00-.52$ & 30 & .02 & .03 & $.00-.10$ & $\begin{array}{l}T(1,33)=5.63 \\
p<.01\end{array}$ \\
\hline Avoidance & .3 & .2 & $.02-.67$ & 34 & .04 & .05 & $.00-.15$ & $\begin{array}{l}T(1,33)=8.49 \\
p<.01\end{array}$ \\
\hline Distraction & .11 & .09 & $.00-.33$ & 33 & .08 & .07 & $.00-.27$ & $\begin{array}{l}T(1,33)=4.50 \\
p<.01\end{array}$ \\
\hline Maternal orientation & .22 & .15 & $.03-.62$ & 34 & .08 & .06 & $.01-.29$ & $\begin{array}{l}T(1,33)=6.08 \\
p<.01\end{array}$ \\
\hline Other-directed comfort seeking & .05 & .06 & $.00-.29$ & 30 & .02 & .03 & $.00-.12$ & $\begin{array}{l}T(1,33)=3.88 \\
p<.01\end{array}$ \\
\hline Other-directed assistance seeking & .07 & .11 & $.00-.51$ & 25 & .008 & .02 & $.00-.11$ & $\begin{array}{l}T(1,33)=3.62 \\
p<.01\end{array}$ \\
\hline \multicolumn{9}{|c|}{ Child composite emotion regulation strategies } \\
\hline Physical strategies composite & .57 & .41 & $.05-1.37$ & 34 & .14 & .13 & $.00-.42$ & $\begin{array}{l}T(1,33)=8.40 \\
p<.01\end{array}$ \\
\hline Comfort strategies composite & .07 & .06 & $.00-.32$ & 31 & .02 & .03 & $.00-.14$ & $\begin{array}{l}T(1,33)=4.33 \\
p<.01\end{array}$ \\
\hline Verbal strategies composite & .29 & .21 & $.04-.84$ & 25 & .09 & .06 & $.01-.30$ & $\begin{array}{l}T(1,33)=5.63 \\
p<.01\end{array}$ \\
\hline
\end{tabular}

Note: Values represent the average proportion of total time across the 24 intervention sessions

$T$-test for composite variables significant with Bonferroni correction at $p<.01$

\section{Results}

Initial descriptive relationships among child negativity, maternal regulation strategies, and child strategies were explored using average total scores of strategy use. These average strategy scores were calculated by adding up each individual's proportion of negative intervals engaging in each strategy across the possible 24 intervention sessions and dividing by the total number of sessions coded for that individual. Subsequent analyses in this section utilize these average proportional scores.

Use of Maternal and Child Emotion Regulation Behaviors

Results showed that children on average had 9.4 sessions with significant distress episodes out of the 24 total sessions with a range of four sessions to 24 sessions. In these sessions, children displayed negativity for $20 \%$ of the time on average with a range of $6-52 \%$ of the time. In an effort to explore individual differences associated with children's negativity, bivariate associations between negativity and child chronological and mental age were tested and no relationship was found. Children most frequently engaged in active strategies (tension release, avoidance, and distraction). Similarly, mothers most frequently engaged in active strategies (redirection of attention, prompting/helping, and physical strategies) during child negativity (Tables 4 and 5).

A dependent samples $t$-test was used to determine whether maternal and child emotion regulation strategies occurred significantly more during episodes of negativity in the child compared to those of non-negativity. Children engaged in all three of the composite child strategies, 
Table 5 Descriptive statistics for maternal emotion regulation strategies and global rating scales

\begin{tabular}{|c|c|c|c|c|c|c|c|c|}
\hline & \multicolumn{4}{|c|}{$\begin{array}{l}\text { Proportion of time during } \\
\text { negative episodes }\end{array}$} & \multicolumn{3}{|c|}{$\begin{array}{l}\text { Proportion of time during } \\
\text { non-negative episodes }\end{array}$} & \multirow[t]{2}{*}{$\begin{array}{l}\text { Dependent samples } \\
T \text { - values }\end{array}$} \\
\hline & M & SD & Range & Freq of moms & M & SD & Range & \\
\hline \multicolumn{9}{|l|}{ Maternal global rating scale } \\
\hline Maternal emotional scaffolding & 3.6 & .07 & $2.45-5$ & N/A & & & & N/A \\
\hline Maternal motivational scaffolding & 3.3 & .5 & $2.25-4.9$ & N/A & & & & N/A \\
\hline \multicolumn{9}{|c|}{ Maternal individual emotion regulation strategies } \\
\hline Prompting/helping & .17 & .11 & $.01-.39$ & 34 & .07 & .07 & $.00-.32$ & $\begin{array}{l}T(1,33)=8.61 \\
p<.01\end{array}$ \\
\hline Following the child's lead & .03 & .04 & $.00-.15$ & 25 & .05 & .03 & $.01-.10$ & $\begin{array}{l}T(1,33)=-2.10 \\
p<.05\end{array}$ \\
\hline Redirection of attention & .19 & .07 & $.07-.37$ & 34 & .1 & .05 & $.03-.23$ & $\begin{array}{l}T(1,33)=6.23 \\
p<.01\end{array}$ \\
\hline Active ignoring & .03 & .04 & $.00-.15$ & 25 & .003 & .005 & $.00-.02$ & $\begin{array}{l}T(1,33)=4.75 \\
p<.01\end{array}$ \\
\hline Reassurance & .1 & .08 & $.00-.27$ & 33 & .01 & .02 & $.00-.08$ & $\begin{array}{l}T(1,33)=6.46 \\
p<.01\end{array}$ \\
\hline Emotional following & .24 & .1 & $.07-.49$ & 34 & .03 & .03 & $.00-.08$ & $\begin{array}{l}T(1,33)=12.69 \\
p<.01\end{array}$ \\
\hline Physical comfort & .07 & .05 & $.00-.17$ & 33 & .01 & .01 & $.00-.05$ & $\begin{array}{l}T(1,33)=6.46 \\
p<.01\end{array}$ \\
\hline Vocal comfort & .04 & .04 & $.00-.15$ & 30 & .008 & .01 & $.00-.03$ & $\begin{array}{l}T(1,33)=4.36 \\
p<.01\end{array}$ \\
\hline \multicolumn{9}{|c|}{ Maternal composite emotion regulation strategies } \\
\hline Vocal strategies composite & .13 & .09 & $.01-.33$ & 34 & .02 & .02 & $.00-.11$ & $\begin{array}{l}T(1,33)=7.56 \\
p<.01\end{array}$ \\
\hline Active strategies composite & .43 & .13 & $.14-.76$ & 34 & .18 & .12 & $.05-.52$ & $\begin{array}{l}T(1,33)=11.77 \\
p<.01\end{array}$ \\
\hline
\end{tabular}

Note: Values represent the average proportion of total time across the 24 intervention sessions

$T$-test for composite variables significant with Bonferroni correction at $p<.01$

including child active strategies, child comfort strategies, and child constructive strategies, significantly more during episodes of negativity. Similarly, mother's engaged in both maternal active strategies and maternal vocal strategies more frequently during episodes of child negativity. Descriptive statistics and $t$-values for maternal and child strategies are presented in Tables 4 and 5 .

\section{Bivariate Associations Among Maternal and Child Emotion Regulation Behaviors}

Controlling for negativity in the child, partial correlations between maternal and child composite variables revealed that child comfort strategies were positively correlated with maternal vocal strategies, $\mathrm{pr}=.38$, and maternal active strategies, $\mathrm{pr}=.36$. Child physical strategies were negatively correlated with child verbal strategies, $\mathrm{pr}=-.46$ (Table 6).
Table 6 Correlations among composite variables

\begin{tabular}{lccccc}
\hline & 1 & 2 & 3 & 4 & 5 \\
\hline 1. Maternal vocal strategies & - & .33 & $.38 * *$ & -.04 & .024 \\
2. Maternal active strategies & & - & $.36 *$ & .24 & -.29 \\
3. Child comfort strategies & & - & .003 & -.08 \\
4. Child physical strategies & & & - & $-.46^{* *}$ \\
5. Child verbal strategies & & & & - \\
$* p<.05 ; * * p<.01$ & & & &
\end{tabular}

Bivariate Associations Between Participant Characteristics and Emotion Regulation Behaviors

The association was tested between all primary study variables and children's behavior problems on the Child Behavior Checklist (CBCL) and mothers' reported stress on the Parenting Stress Index (PSI). As expected, the CBCL 
and PSI were significantly associated, CBCL total scores and scores on the externalizing and internalizing domains were correlated positively with the domains of child stress, parent stress, and total stress on the PSI, $p<.05$.

Maternal vocal strategies (vocal comfort and reassurance) were related negatively to the child domain of stress on the PSI, $r=-.42(p<.05)$. That is, increased childrelated stress as reported by mothers on the PSI was related to mothers' decreased use of vocal strategies. Maternal active strategies (prompting, physical comfort, and redirection) were positively related to CBCL externalizing scores, $r=.47(p<.01)$. Thus, increased ratings of child externalizing problems on the CBCL were related to the mother's increased use of active regulation strategies. There were no relations between children's emotion regulation and negativity behaviors and either the CBCL or PSI.

\section{Growth Curve Analyses}

To explore the change in emotion regulation outcomes across the intervention, growth curve analyses were employed (Mplus Version 4.2, Muthen and Muthen). This type of analysis allows for the examination of individual growth trajectories in outcomes across the intervention. Treating time as a continuous variable further allows for the measurement of outcomes at different time points. This is particularly relevant to the current study as emotion regulation outcomes were coded only during sessions identified with distress episodes, thus not every session was coded or entered into the growth curve analysis. A level-1 model examining the unconditional growth of emotion regulation outcomes across the intervention (time) was utilized.

\section{Growth in Maternal Global Rating Scales Across the Intervention}

A linear growth model significantly described the change in maternal global rating scores of both motivational and emotional scaffolding across the intervention. For motivational scaffolding, results revealed significant positive linear growth over time (Intercept Coefficient $=2.82$; $S E=.14 ; z=20.43 ;$ Slope Coefficient $=.045 ; S E=.01$; $z=4.3$ ). Significant positive growth also was found across the intervention for mothers' emotional scaffolding (Intercept Coefficient $=3.25 ; \quad S E=.15 ; \quad z=21.54 ;$ Slope Coefficient $=.03 ; S E=.006 ; z=4.78)($ See Fig. 1$)$.

\section{Growth in Maternal and Child Emotion Regulation Strategies Across the Intervention}

When the trajectories of linear growth were assessed in maternal and child emotion regulation strategies across the

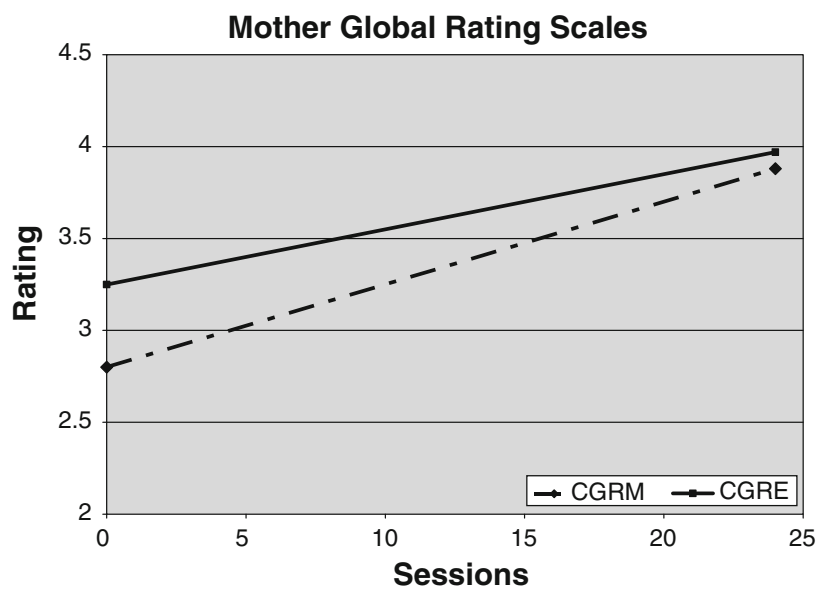

Fig. 1 Growth of global rating scales across the intervention

intervention, results revealed a significant negative linear growth trajectory for maternal emotional following (Intercept Coefficient $=2.87 ; S E=.35 ; z=8.3 ;$ Slope Coefficient $=-.052 ; S E=.02 ; z=-2.32$ ). With respect to children's behaviors, results revealed a significant negative linear growth trajectory for avoidance behaviors (Intercept Coefficient $=3.45 ; S E=.53 ; z=6.48$; Slope Coefficient $=-.055 ; S E=.03 ; z=-2.01)$, and a negative trend for child negativity (Intercept Coefficient $=.1$; $S E=.015 ; z=6.55 ;$ Slope Coefficient $=-.01 ; \quad S E=$ $.001 ; z=-1.72$ ) (See Fig. 2). Linear growth models were found for significant changes in maternal strategy of emotional following, child strategy of avoidance, and a trend for the intensity of facial negativity expressed by the children. In each case there was a negative linear growth trajectory such that mothers decreased emotional following, and children decreased their facial negativity and avoidant strategies.

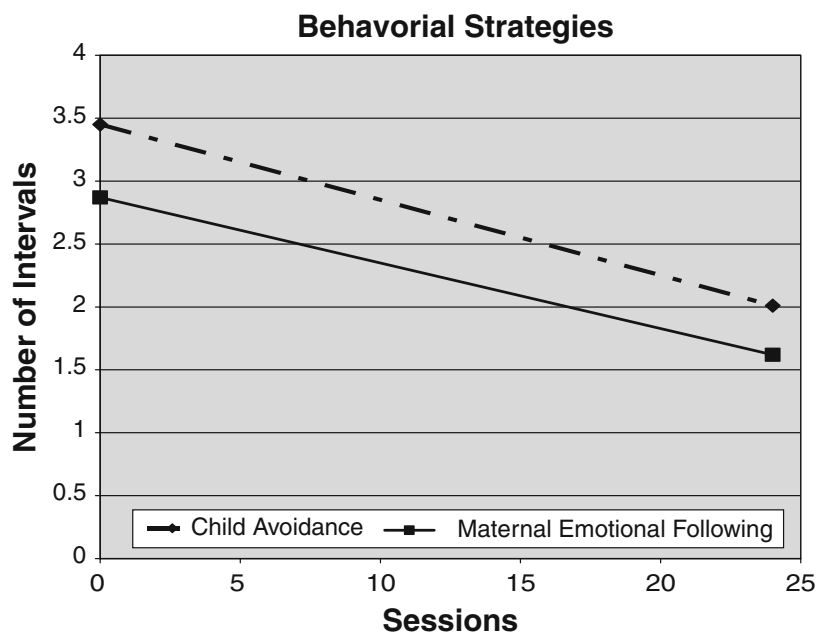

Fig. 2 Growth of behavioral strategies across the intervention 


\section{Discussion}

The present study examined the negative emotional expressions and co-regulation behaviors of mothers and their toddlers with autism during an early intervention targeting social communication behaviors. The study yielded three main findings. The first was that young children with autism display relatively frequent episodes of distress during normal play interactions with their mothers. Recent work has suggested that expressed negativity during early mother-child interactions is a powerful indicator of dysregulation in young children because this context is considered an environment of mutual support and cooperation with relatively few demands placed on the child (NICHD Early Child Care Research Network 2004). Although there was variability in the overall intensity of negative expressions and number of distress episodes across the intervention, almost all of the children in the present study displayed an increased amount of negative arousal during play interactions with their mothers, suggesting a possible profile of dysregulation in young children with autism.

Mothers of these young children with autism engaged in an array of strategies during distress episodes from more active strategies (redirection, prompting, physical behaviors) to more vocal comforting strategies (vocal soothing and reassurance). The strategies they employed were very similar to those of mothers of typically developing toddlers, with one exception. During the toddler years, the typical literature outlines a clear shift in maternal strategy use from more physical and active strategies (e.g., physical comfort and helping) to more passive strategies such as verbal explanations (Grolnick et al. 1998). This decrease in the use of active strategies was not apparent for mothers of toddlers with autism, who continued to use active strategies most frequently throughout the intervention, perhaps due to their children's developmental delays. This finding suggests that mothers in our study were sensitive and responsive to their children's developmental needs.

In turn, children with autism engaged in a range of appropriate active (distraction, avoidance, tension release) and constructive (orienting to mom, and assistance seeking) regulation strategies. These strategies fit closely with the developmental profile of emotion regulation in typical toddlers. Thus, in toddlerhood, both typical toddlers and toddlers with autism view mothers as a source of assistance and use strategies to recruit parental support and assistance, such as help-seeking and orienting to them (Kopp 1989). Although the next developmental shift for typical children is to begin to use sophisticated verbal strategies such as symbolic/verbal self-soothing, such strategies were used infrequently by children in the present study. It may be that the expressive language delays of children in the present study (expressive language age $<20$ months) affect their higher-order regulatory capacities. Future work should examine the development of higher-order verbal strategies for emotion regulation in children with autism with greater verbal ability.

Our results also show that strategies were used significantly more during episodes of negativity than non-negativity. These findings support the validity of selecting and coding for specified emotion regulation behaviors found in the typical literature. Thus, these exploratory analyses demonstrate that emotion regulation is a construct that can be measured in children with autism, and the development of emotion regulation may be more similar to, than different from, typical children.

A second finding of the study was that specific characteristics in the child with autism and the mother were associated with emotion regulation outcomes. Greater child externalizing behaviors were associated with higher levels of maternal stress and the use of more active regulatory strategies, further supporting the dyadic nature of child and maternal behaviors. Kasari et al. (1988) also found that although parents of children with autism, developmental delays, and typical children all scored similarly on a measure of responsiveness to their children, mothers of children with autism engaged in a higher frequency of physical holding/comfort behaviors. Although the direction of effects is unclear, mothers may use more of these active strategies for children with more behavior problems as a way to facilitate their children's regulation. In addition, higher scores on parenting stress were associated with mothers who engaged in fewer vocal regulatory strategies with their children. In summary, mothers who see their children as having more behavior problems are more stressed and use fewer vocal strategies, but more active strategies while interacting with their toddlers with autism.

Finally, this study demonstrates improvements in maternal co-regulation strategies, and child emotion regulation of negativity as a result of a brief, 8-week targeted joint engagement intervention. Changes were noted in global rating scales and in coded discrete behaviors. Both the motivational and emotional global scales measured mothers' abilities to initiate and maintain episodes of joint engagement using sensitive and responsive parenting during the intervention sessions. These intervention topics while very important to engagement are also important to the co-regulation of emotions between mothers and their children with autism. At the most basic level, the mother's ability to redirect attention away from a source of child distress and reengage the child in an ongoing play activity appears to be an important regulatory skill. In the typical literature this sensitive and responsive caretaking has been found to be related to the socialization of emotions and emotion regulation (Bridges and Grolnick 1995; Fish et al. 1991). Thus, it is likely that mothers' improvements on the 
ratings of motivational and emotional scaffolding in the present study are related to the socialization of emotion regulation in young children with autism.

Behaviorally coded discrete behaviors also showed change across the intervention, in that child expressed negativity and avoidance and maternal emotional following decreased. Grolnick et al. (1998) found a developmental shift in the use of emotional following in mothers of typical children. Mothers used more of these strategies with 12-24 month olds than they did for children ages 24-36 months. All of the children but one in the present study fell between the chronological ages of 24-36 months. In addition, some believe that strategies that call excessive attention to or extend and elaborate upon the child's distress by asking questions may minimize the child's experience and over time may cause the child to hide his/her emotions or avoid emotion eliciting experiences (Eisenberg et al. 1996). In fact, recent work by Spinrad et al. (2004) found that maternal questioning of the child's emotions was related to the child's lack of self-regulation skills during a disappointment task. In combination these findings suggest multiple reasons for the decrease in maternal emotional following reported in the present study.

In summary, findings from this study suggest that children with autism are at risk for dysregulation and that early mother-child interactions may be an ideal context for the socialization of emotion regulation. Children with ASD display relatively high levels of negativity in play interactions with their mothers. Additionally, both mothers and children appear to engage in a range of specific emotion coregulation strategies during these negative distress episodes that are quite similar to the strategies employed by typical mother-child dyads. Maternal regulation also appears to be related to both child and maternal characteristics. Lastly, intervention outcomes provide evidence for the effectiveness of an early mother-driven social-communication intervention in decreasing negativity and supporting emotion regulation capabilities in children with autism. Future work in this area should focus on the design of specific intervention components that target emotion regulation.

Open Access This article is distributed under the terms of the Creative Commons Attribution Noncommercial License which permits any noncommercial use, distribution, and reproduction in any medium, provided the original author(s) and source are credited.

\section{References}

Abidin, R. R. (1982). Parenting stress and utilization of pediatric services. Children's Health Care, 11, 70-73.

Abidin, R. R. (1983). Parenting stress index manual. Charlottesville, VA: Pediatric Psychology Press.
Achenbach, T. M., Edelbrock, C., \& Howell, C. T. (1987). Empirically based assessment of the behavioral/emotional problems of 2- and 3- year-old children. Journal of Abnormal Child Psychology, 4, 629-650.

Adamson, L., McArthur, D., Markoc, Y., Dubar, B., \& Bakeman, R. (2001). Autism and joint attention: Young children's responses to maternal bids. Applied Developmental Psychology, 22, 439-453.

Aldred, C., Green, J., \& Adams, C. (2004). A new social communication intervention for children with autism: Pilot randomized controlled treatment study suggesting effectiveness. Journal of Child Psychology and Psychiatry, 45, 1420-1430.

Bailey, D., Hatton, D., Mesibov, G., \& Ament, N. (2000). Early development, temperament, and functional impairment in autism and Fragile X syndrome. Journal of Autism and Developmental Disorders, 30, 49-59.

Baker, J. K., \& Crnic, K. A. (2005). The relation between mothers' reports of family-of-origin expressiveness and their emotionrelated parenting. Parenting: Science and Practice, 5, 333-346.

Belsky, J. (1984). The determinants of parenting: A process model. Child Development, 55, 83-96.

Bieberich, A., \& Morgan, S. B. (2004). Self-regulation and affective expression during play in children with autism or Down syndrome: A short-term longitudinal study. Journal of Autism and Developmental Disorders, 34, 439-448.

Bridges, L. J., \& Grolnick, W. S. (1995). The development of emotional self-regulation in infancy and early childhood. In N. Eisenberg (Ed.), Social development. Review of personality and social psychology (pp. 185-211). Thousand Oaks, CA: Sage Publications.

Capps, L., Kasari, C., Yirmiya, N., \& Sigman, M. (1993). Parental perception of emotional expressiveness in children with autism. Journal of Consulting and Clinical Psychology, 61, 475-484.

Drew, Auriol., Baird, Gillian., Baron-Cohen, Simon., Cox, Antony., Slonims, Vicky., Wheelwright, Sally., et al. (2002). A pilot randomised control trial of a parent training intervention for preschool children with autism: Preliminary findings and methodological challenges. European Child and Adolescent Psychiatry, $11,266-272$.

Eisenberg, N., Fabes, R. A., \& Murphy, B. C. (1996). Parents' reactions to children's negative emotions: Relations to children's social competence and comforting behavior. Child Development, 67, 2227-2247.

Eunice Kennedy Shriver National Institute of Child Health and Human Development; National Institute of Mental Health. (2009). Caregiver buy-in affects joint attention intervention of toddlers with autism. In ClinicalTrials.gov [Internet]. Bethesda (MD): National Library of Medicine (US). 2003 - [cited 2009 Aug 21]. Available from: http://clinicaltrials.gov/show/NCT00 065910:NLM Identifier:NCT00065910.

Fish, M., Stifter, C. A., \& Belsky, J. (1991). Conditions of continuity and discontinuity in infant negative emotionality: Newborn to five months. Child Development, 62, 1525-1537.

Goldsmith, H. H., \& Rothbart, M. K. (1996). The laboratory temperament assessment battery (LAB-TAB): Locomotor version 3.0. technical manual. Department of Psychology, University of Wisconsin, Madison, WI. (plus corresponding version of the prelocomotor battery manual)

Grolnick, W. S., Bridges, L. J., \& Connell, J. P. (1996). Emotion regulation in two-year-olds: Strategies and emotional expression in four contexts. Child Development, 67, 928-941.

Grolnick, W. S., Kurowski, C., McMenamy, J. M., Rivkin, I., \& Bridges, L. J. (1998). Mothers' strategies for regulating their toddlers' distress. Infant Behavior and Development, 21, 437-450.

Kasari, C., Freeman, S. F. N., \& Paparella, T. (2006). Joint attention and symbolic play in young children with autism: A randomized 
controlled intervention study. Journal of Child Psychology and Psychiatry, 47, 611-620.

Kasari, C., \& Sigman, M. (1997). Linking parental perceptions to interactions in young children with autism. Journal of Autism and Developmental Disorders, 27, 39-57.

Kasari, C., Sigman, M., Mundy, P., \& Yirmiya, N. (1988). Caregiver interactions with autistic children. Journal of Abnormal Child Psychology, 16, 45-56.

Konstantareas, M., \& Stewart, K. (2006). Affect regulation and temperament in children with autism spectrum disorder. Journal of Autism and Developmental Disorders, 36, 143-154.

Konstantareas, M., Zajdeman, H., Homatidis, S., \& McCabe, A. (1988). Maternal speech to verbal and higher functioning versus nonverbal and lower functioning autistic children. Journal of Autism and Developmental Disorders, 18, 647-656.

Kopp, C. B. (1989). Regulation of distress and negative emotions: A developmental view. Developmental Psychology, 25, 343-354.

Lord, C., Rutter, M., \& Couteur, A. (1994). Autism diagnostic interview- revised: A revised version of a diagnostic interview for caregivers of individuals with possible pervasive developmental disorder. Journal of Autism and Developmental Disorders, 24, $659-685$.

Lord, C., Rutter, M., Goode, S., Heemsbergen, J., Jordan, H., Mawhood, L., et al. (1989). Autism diagnostic observation schedule: A standardized observation of communication and social behavior. Journal of Autism and Developmental Disorders, $19,185-212$.

Maslin-Cole, C., \& Spieker, S. J. (1990). Attachment as a basis for independent motivation: A view from risk and nonrisk samples. In M. T. Greenberg, D. Cicchetti, \& E. M. Cummings (Eds.), Attachment in the preschool years: Thoery, research and intervention (pp. 245-272). Chicago, IL: University of Chicago Press.

Morales, M., Mundy, P., Crowson, M. M., Neal, A. R., \& Delgado, C. (2005). Individual differences in infant attention skills, joint attention, and emotion regulation behavior. International Journal of Behavioral Development, 29, 259-263.

Mullen, E. M. (1995). Mullen scales of early learning. Minnesota: American Guidance Service.
NICHD Early Child Care Research Network. (2004). Affect dysregulation in the mother-child relationship in the toddler years: Antecedents and consequences. Development and Psychopathology, 16, 43-68.

Raver, C. (1996). Relations between social contingency in motherchild interaction and 2-year-olds' social competence. Developmental Psychology, 32, 850-859.

Siller, M., \& Sigman, M. (2002). The behaviors of parents of children with autism predict the subsequent development of their children's communication. Journal of Autism and Developmental Disorders, 32, 77-89.

Skovgaard, A., Houmann, T., Landorph, S. L., \& Christiansen, E. (2004). Assessment and classification of psychopathology in epidemiological research of children 0-3 years of age. European Child and Adolescent Psychiatry, 13, 337-346.

Spinrad, T. L., Stifter, C. A., Donelan-McCall, N., \& Turner, L. (2004). Mothers' regulation strategies in response to toddlers' affect: Links to later emotion self-regulation. Social Development, 13, $40-55$.

Stansbury, K., \& Zimmermann, L. K. (1999). Relations among child language skills, maternal socialization of emotion regulation, and child behavior problems. Child Psychiatry and Human Development, 30, 121-142.

Thompson, R. (1994). Emotion regulation: A theme in search of definition. Monographs of the Society for Research in Child Development, 59(2-3), 25-52.

Tomanik, S., Harris, G., \& Hawkins, J. (2004). The relationship between behaviors exhibited by children with autism and maternal stress. Journal of Intellectual and Developmental Disability, 29, 16-26.

Watson, L. (1998). Following the child's lead: Mothers' interactions with children with autism. Journal of Autism and Developmental Disorders, 28, 51-59.

Yirmiya, N., Kasari, C., Sigman, M., \& Mundy, P. (1989). Facial expressions of affect in autistic, mentally retarded and normal children. Journal of Child Psychology and Psychiatry and Allied Disciplines, 30, 725-735. 